$\xi=-1$

\title{
Model Artificial Intelligent in E-Learning using Fuzzy Logic (Case Study Sasmoko.Com)
}

\author{
Emny Harna Yossy ${ }^{1,6}$, Sasmoko $^{2,6 *}$, Dwi Listriana Kusumastuti ${ }^{3,6}$, Sucianna Ghadati Rabiha ${ }^{4,6}$, Yasinta Indrianti ${ }^{5,6}$ \\ ${ }^{1}$ Computer Science Department, School of Computer Science, Bina Nusantara University, Jakarta, Indonesia \\ ${ }^{2}$ Primary Teacher Education Department, Faculty of Humanities, Bina Nusantara University, Jakarta, Indonesia \\ ${ }^{3}$ Information System Department, School of Information Systems, Bina Nusantara University, Jakarta, Indonesia \\ ${ }^{4}$ Information System Department, Binus Online Learning, Bina Nusantara University, Jakarta, Indonesia \\ ${ }^{5}$ Faculty of Social, Podomoro University, Jakarta, Indonesia \\ ${ }^{6}$ Research Interest Group in Educational Technology, Bina Nusantara University, Jakarta, Indonesia \\ *Corresponding author E-mail: sasmoko@binus.edu
}

\begin{abstract}
The advancement of information technology has been maximally utilized in the world of education, especially in the learning process. One form is e-learning. In its development, e-learning has several problems when faced with the background and needs of students who take part in learning. These differences affect the effectiveness of learning because not all students have the same learning style. To overcome these problems, researchers tried to use fuzzy logic methods. Fuzzy logic is chosen to answer the uncertainty that occurs in learning subjective student characters. Therefore, the study was conducted on one e-learning website called sasmoko.com. The e-learning website is a research method course where students from various backgrounds and needs are used. In this study a model was proposed in assessing student characters on the sasmoko.com website.
\end{abstract}

Keywords: Artificial Intelligent; E-Learning; Fuzzy Logic.

\section{Introduction}

The advancement of information technology has been maximally utilized in the world of education, especially in the learning process. One form is e-learning. E-learning involves computers and networks that are activated to transfer skills and knowledge [1]. Therefore, e-learning offers convenience to the domain of knowledge and learning processes where and whenever by its users [2]. With the offer, Sasmoko applied the e-learning method in the course he taught namely the research method. He built an application called sasmoko.com. Sasmoko.com was built in 2014 . can be accessed by lecturers and students who take research method courses [3].

Students who follow sasmoko.com have different backgrounds, abilities and needs. Therefore, e-learning systems and applications must offer dynamic adaptation for each student. Adaptation is done through a student model. The student model is a core component in intelligent or adaptive guidance systems that are responsible for identifying and reasoning the level of student knowledge, misconceptions, abilities, preferences and needs. However, student modeling in many cases is related to uncertainty [4]. These problems are based on human subjectivity and conceptualization, one approach that might be fuzzy logic. Fuzzy logic is chosen to answer the uncertainty that occurs in learning subjective student characters. With the fuzzy logic approach students are expected to be independent in determining the progress of learning and finding a way out to overcome learning difficulties. In addition, students can be independent without doing face-to-face learning with this educational technology.
Therefore, this research was conducted so that the Sasmoko.com website can be one of the e-learning applications that understand the differences in backgrounds, abilities and needs. The research method used is fuzzy logic which is part of artificial intelligence. This study is about a framework in assessing student characters on the Sasmoko.com website using fuzzy logic that can predict the character of students in attending lectures using the Sasmoko.com application.

\section{Literature Review}

\subsection{Sasmoko.Com}

The Sasmoko.com is a website built in 2014 initiated by Sasmoko, one of the Professors owned by Bina Nusantara University, Indonesia. Sasmoko.com site is used to conduct the learning process Research Methodology course. Site address: http://sasmoko.com. This app was built using HTML 5 for web display and MySQL for database. Applications can be accessed by administrators, faculty, students and guests. Sasmoko.com has several menus, among others: 1) Home: page to display the latest news and photos displayed in the slide bar; 2) E-learning: pages for teaching research methodology with multiple sub menus; 3) References: page to display a list of reference links related to lectures; 4) Data: page to display data; 5) Profile: page to display user profile and user can edit profile and change password; 6) Log In: page to display user login page consisting of username and password form; 7) Log Out: the page to process out of the system network on sasmoko.com site [1]. 


\subsection{E-Learning}

The development of Internet technology led to the many choices of approaches to learning methods on education [5], one of which is called e-learning. E-learning is a network-based learning model using internet or intranet and its implementation is supported by technologies such as telephone, audio, videotape, satellite transmission or computer peripheral [6]. According to the European Commission, e-learning is a method of learning based on Internet and multimedia technologies to improve the quality of teaching through the provision of access to educational resources and services and enable remote evaluation, information exchange and collaboration between students and lecturers [7]. In addition, Elearning is learning that is structured with the aim of using an electronic or computer system so that it be able to support the learning process [8], the process of distance learning by combining principles in the learning process with technology [9], and learning systems that are used as a means for teaching and learning carried out without having to face to face directly between the teacher and students [10].

E-Learning has characteristics including: E-learning is networked, which makes it able to improve quickly, store or re-create, distribute, and share learning and information. E-learning characteristics include: utilizing electronic technology services, utilizing computer excellence, using independent teaching materials and then storing them on a computer, so that they can be accessed by lecturers and students anytime and anywhere, and utilizing learning schedules, curriculum, learning progress, and matters relating to the administration of education can be viewed at any time on the computer [11].

\subsection{Artificial Intelligence}

Artificial technology that simulates human intelligence, namely how to define and try to solve problems using a computer by imitating how humans solve quickly. The branches of artificial intelligence are: expert systems, artificial neural networks, fuzzy logic, genetic algorithms, case-based reasoning, intelligent software agents, data mining, language technology. In this study will use fuzzy logic because it allows membership values between 0 and 1 , gray level and black and white, and in linguistic form, uncertain concepts such as "little", "decent", and "very". He deals with fuzzy sets and probability theory [2].

\subsubsection{Fuzzy Logic}

Fuzzy logic was introduced by Zadeh to encounter imprecision and uncertainty [12]. It deals with reasoning that is approximate rather than fixed and exact. It is a precise logic of imprecision and approximate reasoning [13]. In other words, fuzzy logic able to reason and make rational decisions in circumstances of imprecision, uncertainty, human subjectivity, incomplete information and deficient computations [14]. The basic element of the fuzzy logic theory is the fuzzy set. A fuzzy set describes a characteristic, thing, fact or state. The ability of fuzzy logic to handle the uncertainty, imprecise and incomplete data, and information that is characterized by human subjectivity makes it useful in many human-centric fields [15]. Fuzzy Logic has categorizes the applications in: approximation; clustering; control; databases; decision making; embedded agents; health care; hidden Markov models neural networks; noise cancellation; pattern classification; quality control; spatial query; wireless communications [16].

In addition, fuzzy set theory has been applied in education and educational systems. For the fuzzy logic the fuzzy knowledge state definer (FuzKSD) module of a web-based educational application for individualized instruction on the domain of programming languages were built. FuzKSD is the basis for providing personalized tutoring to each learner, identifying and updating the student's knowledge level. However, the module's ability to recognize the user's changeable states (like the knowledge level) and the existing dependences among the elements (like concepts, preferences, events) makes this particular module a novel generic tool for adaptive processes concerning user modeling $[17,18]$.

As for similar research, among others, research on the rule-based fuzzy logic for the automatic learning process in an e-learning environment that discusses [2], an adaptive fuzzy logic based system for improved knowledge delivery within intelligent e-learning platforms ${ }^{1}$, study the demand for computer programming professionals has enlarged speedily [19], as a nearly global language, English as a Foreign Language (EFL) programs are essential for people wishing to learn English [20], the e-learners"e excellence can be improved by recommending suitable e-contents available in e-learning servers that are based on investigating their learning styles [21], this paper considers the adaptive fuzzy robust control problem for a class of single-input and single-output (SISO) stochastic nonlinear systems in strict feedback form, Fuzzy Cognitive Maps (FCM) have found favor in a variety of theoretical and applied contexts that span the hard and soft sciences [22], an adaptive fuzzy output feedback control approach with prescribed performance is proposed for a class of uncertain nonlinear strictfeedback systems with unmeasured situation [23].

\section{Research Methodology}

The research method used is the study of literature review and modeling. The literature study was conducted on the concept of elearning, artificial intelligence and fuzzy logic, and various studies on artificial intelligence model in e-learning that have been done by previous researchers. The information obtained is the methods used in compiling the model of artificial intelligence on e-learning, fuzzy logic on e-learning and relevant information. Based on these data, a model whose criteria are taken from existing methods. The expected results are the design of the artificial intelligence model on e-learning with the sasmoko.com case study.

\section{Proposed System}

The proposed system is derived from the incorporation of the Fuzzy Knowledge System Definer (FuKSD) and Fuzzy Logic System (FLS) methods because the researcher can find out about the basis for providing personalized tutoring to each learner, identifying and updating the student's knowledge level found in FuKSD and learn the user preferred knowledge to generate a personalized learning environment obtained in Fuzzy Logic System. The proposed system proposed as follows:

a. Fuzzy Logic for Knowledge Representation

Knowledge domain representation contains knowledge or behavior that represents expertise in a field that is taught. This domain is the basis for the representation of learner knowledge, which is usually done as part of the knowledge domain.

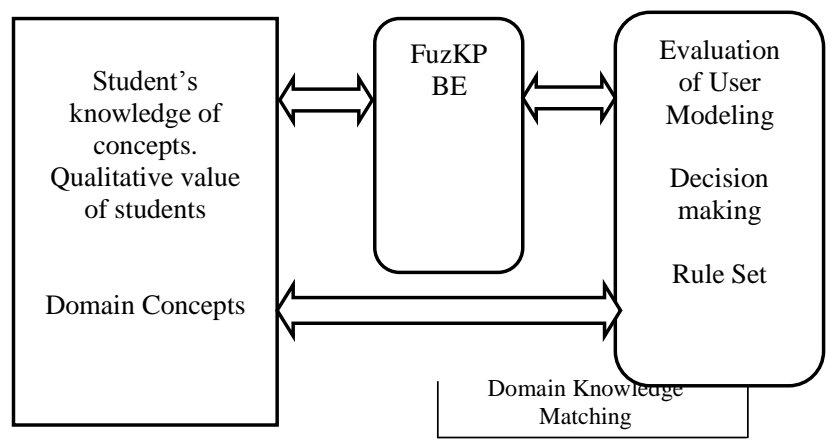

Fig. 1: Rule based FuzKPBE process ${ }^{2}$

To enable communication between systems and learners at the 
content level, the domain model of the system must be sufficient to form the conclusions and relationships of domain entities with the mental domain of human expertise. This technique makes the learning needs of students more easily met with a variety of educational materials accordingly.

b. Domain Knowledge Representation using Fuzzy

The concept of a domain is a learning material as a guide that represents the relationship between the concepts of learning materials. The relationship between the concepts of instructional materials illustrates the sequence of domain concepts to be conveyed and the structure of learning materials, as the dependence of knowledge. Specifically, there are three types of relationships between concepts: "precede" which states the order in which each domain concept of instructional material should be taught. A domain concept is influenced by the level of knowledge of the concept of the related domain. In other words, they describe the "impact strength" of the domain concept on related concepts. Certain numbers are only positive [24].
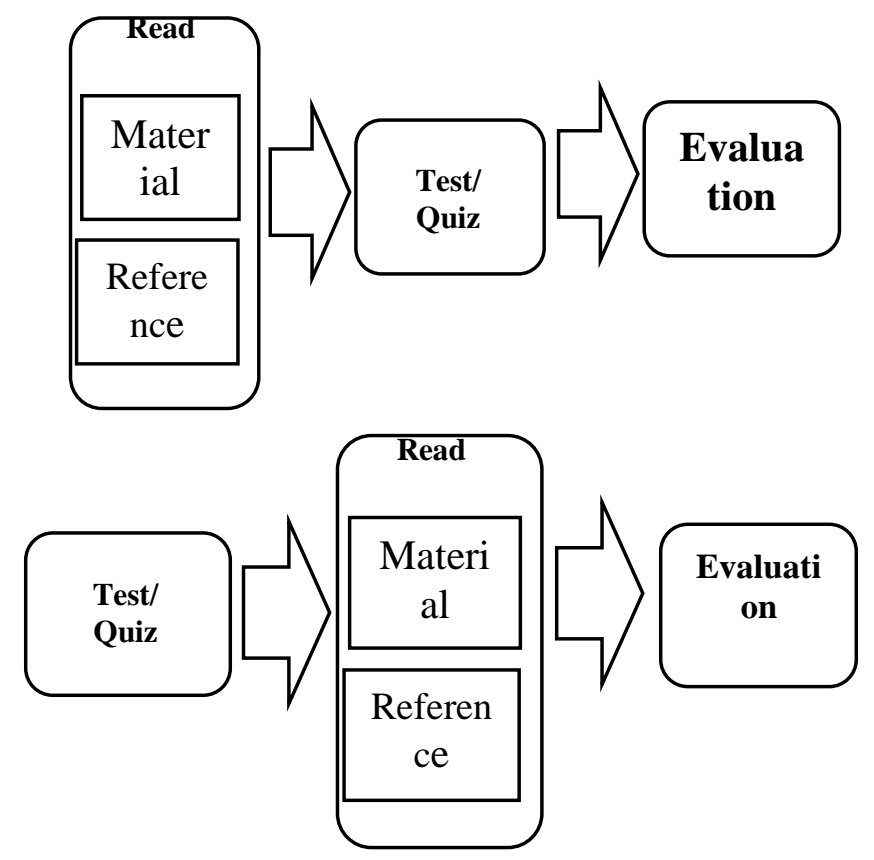

Fig. 2: Concept similarity in domain in sasmoko.com.

c. Domain of the Research Metodology

This model is used for courses. Research methodology where students have their own uniqueness in understanding and completing research concepts. The method used to solve problems in the lesson also varies depending on student habits. For example, the sequence of conducting research, the method used in the study up to the way students conduct experiments on research.

d. Fuzzy Logic for automatically learning Process of a Student The rule-based fuzzy logic system is used to model the cognitive state of learners in studying the research methodology. This system automatically forms the learning model so that it can present the process done by the students. The operation of FLSs is based on rules. The rule is expressed as a collection of IFTHEN statements. The rule-based fuzzy logic module is responsible for identifying and updating the student's knowledge level of all concepts from the knowledge domain [25]. The mechanism used to identify the characteristics of learners, through several stages below:

a. Capturing and analyzing the input and the output data Capturing and analyzing input and output data Initially, our system collects and captures student data through assessing the requirements for the delivery of student knowledge in addition to their characteristics in an online learning environment. At this stage the System will create and study the needs of descriptive models and characteris- tics of students' knowledge delivery; this is achieved through the data collected so to generate a set of multiinput data pairs and outputs.

After the collection of inputs and outputs then the data is collected and categorized through the relevant fuzzy membership function. This stage gives the quantification of raw input and output values then converts them into linguistic labels, for example very low. / low and high / very high. This is achieved through the design of membership functions for input and output.

b. Fuzzy Rule Extraction

Known rules are collected through a membership function then combined with input / output data to determine student behaviour. The method in this system will learn the rules of the data based on the developed and expanded version of the Mendal-Wang approach [26, 27]. This is recognized as a one-pass approach centered on collecting fuzzy rules from a group of data being examined. The 'antecedent and consequent fuzzy' rule divides the output space and input into the fuzzy area.

c. The Customisation of the Knowledge delivery to the students

Fuzzy rules are taken from student input and output data allowing the proposed system to identify and study the delivery requirements of students' knowledge and characteristics. Thus, this system is then used to readjust the online learning environment with special consideration of student needs. Initially, the system initiates action through monitoring student variables, and accordingly impacts the instructional online environment with special consideration for the learning approach of individual student preferences.

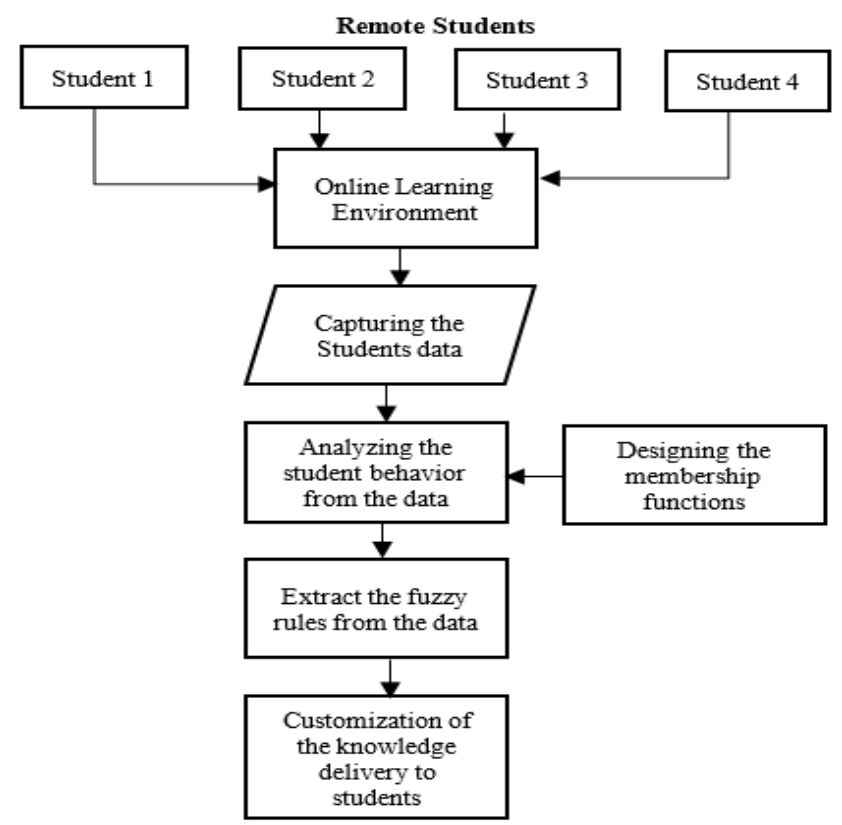

Fig. 3: An overview on the proposed fuzzy logic based systems for improved knowledge delivery within intelligent e-learning platforms (sasmoko.com).

\section{Conclusion}

The fact that a learner accepts new concepts while being taught, so that the learner has his or her own ability to understand the material presented. In these paper fuzzy logics is used to know the characteristics of knowledge and ability of the students in accordance with the concept of the domain presented. The teaching process can change a user's knowledge status. Characteristics of 
knowledge and ability will be used to improve the existing process in e-learning so to produce a supportive learning environment.

\section{Future Work}

The following research that can be done include: evaluation model artificial intelligent in e-learning application for sasmoko.com and perform analysis to prove that the characteristics of students can be predicted in following the learning on the website sasmoko.com.

\section{Acknowledgment}

The research was funded by Bina Nusantara University with a Binus Grant fund for the period of 2018. The object of the research was the sasmoko.com website with the address https://sasmoko.com which was built by Prof. Sasmoko, one of the Professors at Bina Nusantara University.

\section{References}

[1] Almohammadi K \& Hagras H (2013), An Adaptive Fuzzy Logic Based System for Improved Knowledge Delivery within Intelligent E-Learning Platforms. IEEE Int Conf Fuzzy Syst.

[2] Priya MR \& Keerthy G (2015), Rule-Based Fuzzy Logic for Automatic Learning Process in an E-Learning Environment. Int $J$ Adv Res Comput Commun Eng. 4(7).

[3] Sasmoko \& Friend. Sasmoko Website [Internet]. 2014. Available from: sasmoko.com

[4] Chrysafiadi K \& Virvou M (2014), Fuzzy Logic for adaptive instruction in an e-learning environment for computer programming. 6706(c):1-21.

[5] Harrati N. Bouchrika I, Tari A \& LA (2016), Exploring user satisfaction for e-learning systems via usage-based metrics and system usability scale analysis. 2016. Comput Human Behav. 61:463-71.

[6] Kusumastuti DL, Tjhin VU \& Soraya K (2017), The Role of Mobile Devices to Improve Student Learning Motivation on Distance Learning. Proc 2017 Int Conf Inf Technol ACM. 325-9.

[7] Dominici G \& Palumbo F (2013), How to build an e-learning product: factors for student/customer satisfaction. Bus Horiz. 56:87-96.

[8] Allen M (2013), Michael Allen's Guide to E-learning. Canada: John Wiley \& Sons.

[9] Chandrawati SR (2010), Pemanfaatan E-learning dalam Pembelajaran. 8(2). Available from: http://jurnal.untan.ac.id/

[10] Andriansyah I (2013), Eksplorasi Pola Komunikasi dalam Diskusi Menggunakan Moodle pada Perkuliahan Simulasi Pembelajaran Kimia. Universitas Pendidikan Indonesia.

[11] Rosenberg MJ (2001), E-Learning: Strategies for Delivering Knowledge in the Digital Age. New York: NY: McGraw-Hill Companies, Inc. 343 p.

[12] Zadeh L (1965), Fuzzy Sets. Inf Control. 8:338-53.

[13] Zadeh L (1975), The Concept of a Linguistic Variable and Its Application to Approximate Reasoning. Inf Sci. 8(3):199-249.

[14] Zadeh L (2001), A New Direction in Ai: Toward a Computational Theory of Perceptions. AI Magazine. 73.

[15] Chysafiadi K \& Virvou M (2014), Fuzzy logic in Student Modeling. In: Advanced in Personalized Web-Based Education

[16] Mendel J (2007), Type-2 Fuzzy Sets and System: An Overview. IEE Computational Intelligence. 20-9.

[17] Chrysafiadi K \& Virvou M (2012), Evaluating the integration of fuzzy logic into the student model of a web-based learning environment. Expert Syst Appl. 39(18):13127-34.

[18] H. Song CM, Roel W \& Shen Z (2010), Implementation of fuzzy cognitive maps based on fuzzy neural network and application in prediction of time series. IEEE Trans Fuzzy Syst. 18:233-50.

[19] Tung-Cheng Hsieh et al. (2013), Designing and Implementing a Personalized Remedial Learning System for Enhancing the Programming Learning. J Educ Technol Soc. 16(4).

[20] Tzone-I Wang et al. (2012), A Fuzzy Logic-based Personalized Learning System for Supporting Adaptive English Learning. Educ Technol Soc.
[21] Deborah LJAA (2015), Fuzzy-Logic Based Learning Style Prediction in E-Learning using Web Interface Information. Acad Proceeding Eng Sci.

[22] Gray S (2013), Fuzzy Cognitive Maps as Representations of Mental Models and Group Beliefs. Springer Link. 29-48 p.

[23] Zhang L, Tong S \& Li Y (2014), Adaptive Fuzzy Output-Feedback Control with Prescribed Performance for Uncertain Nonlinear Systems. Int J Fuzzy Syst. 16(2).

[24] Chrysafiadi K \& Virvou M (2012), Using Fuzzy Cognitive Maps for the Domain Knowledge Representation of an Adaptive ELearning system. Proc 10th Jt Conf Known - Based Softw Eng, Rhodes, Greece. 257-265.

[25] Mendel JM (2001), Uncertain Rule-Based Fuzzy Logic Systems: Introduction and New Directions. Englewood Cliffs, NJ, USA: Prentice-Hall.

[26] Wang LX (2003), The MW Method Completed: A Flexible System Approach to Data Mining. IEEE Trans Fuzzy Syst. 11(6):68-782.

[27] Wang LX \& Mendel JM (1992), Generating Fuzzy Rules by Learning from Examples. IEEE Trans Syst Man Cybern. 22(6):1414-1427. 